\title{
Andreas Vesalius (1514-1564), Padua, and the fetal "shunts"
}

\section{P M Dunn}

Arch Dis Child Fetal Neonatal Ed 2003;88:F157-F159

Three remarkable medical anatomists working in Padua during the 16th century described the anatomy of the fetal cardiovascular system, thus laying the foundation for William Harvey's discovery and description of the fetal circulation in the following century.

\footnotetext{
$\Lambda^{n}$ ndreas Vesalius (fig 1) was born in Brussels in 1514 into a family with longstanding medical associations with the Holy Roman Emperor's court. ${ }^{1}$ His father was pharmacist to Charles V, and his mother English. Andreas' medical training began at the University of Louvain (1529-1533), continued in Paris under Sylvius (1533-1536), and was completed in the renowned University of Padua, where in 1537 he attained the degree of MD at the age of 23. He was at once appointed lecturer in surgery with responsibility for giving anatomical demonstrations. During the next few years in Padua, he applied himself to dissection of the human body and to the preparation of a textbook, complete with 277 superb engravings. These were probably drawn by his fellow countryman, Jan Stephan van Calcar, who was working at the time in Titian's studio in Venice. This magnum opus, De humani corporis fabrica (The fabric of the human body $)^{2}$ was dedicated to Charles V, and was published in Basel in 1543 when he was 28. It revolutionised anatomy, surgery, and scientific teaching in general. The following short passage is a sample of his writing.
}

\section{On resuscitation ${ }^{2}$}

"But that life may, in a manner of speaking, be restored to the animal, an opening must be attempted in the trunk of the trachea, into which a tube or reed or cane should be put; you will then blow into this so that the lung may rise again and the animal take in air. Indeed, with a single breath in the case of this living animal, the lung will swell to the full extent of the thoracic cavity and the heart become strong and exhibit a wondrous variety of motions... when the lung long flaccid has collapsed, the beat of the heart and arteries appears wavy, creepy, twisting, but when the lung is inflated, it becomes strong again and swift and displays wondrous variations . . . and as I do this, and take care that the lung is inflated at intervals, the motion of the heart and arteries does not stop."
According to Franklin, Vesalius did not in the Fabrica appreciably advance knowledge of the fetal cardiovascular system; for there was no mention of the fetal shunts. However, he did contradict Galen's statement that there were communications between the two ventricles. ${ }^{3}$ Later in 1564, in a response to Fallopius, he claimed that he had been well aware in 1543 of the existence of the ductus venosus and ductus arteriosus and that the Fabrica did not represent all his knowledge.

For many hundreds of years Galen (AD 130200) had been regarded as the undisputed authority on anatomy. Vesalius was able to correct a number of Galenic errors, and, because of this, was bitterly attacked, especially by his old teacher Sylvius, who accused him of poisoning the air of Europe. Disgusted, he burnt many of his manuscripts and left Padua to return to Brussels and marry Anne van Hamme before becoming court physician to Charles V in 1544. His medical and surgical practice flourished, and, among other successes, he described a new treatment for syphilis and introduced the surgical drainage of emphysema. In 1556, Vesalius was made a count by Charles $\mathrm{V}$ and provided with a lifetime pension. Three years later he moved with his wife and daughter to Madrid to become physician to Charles' son, Phillip II. In 1564 he was charged

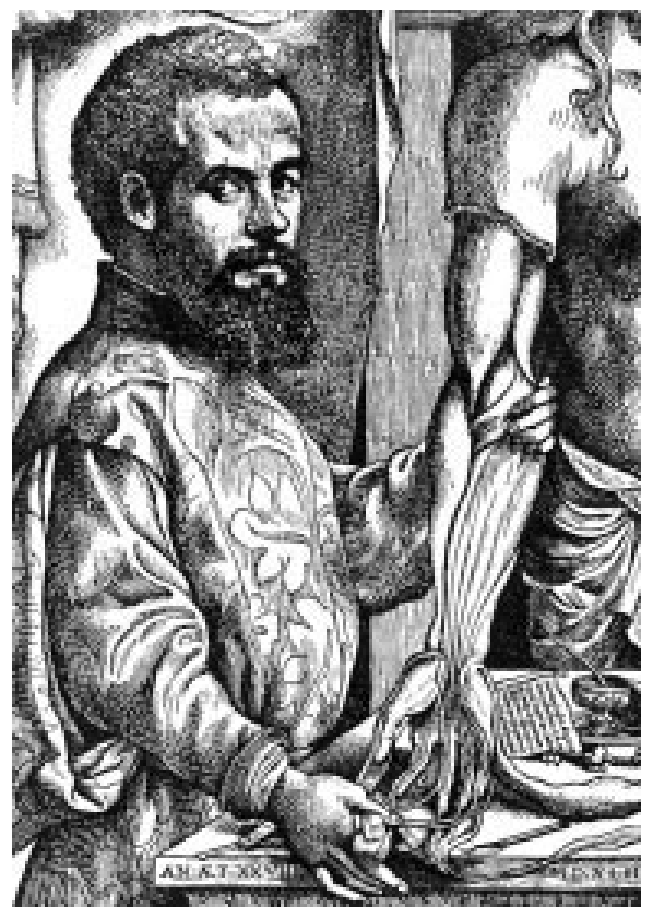

Figure 1 Andreas Vesalius, 1514-1564. 


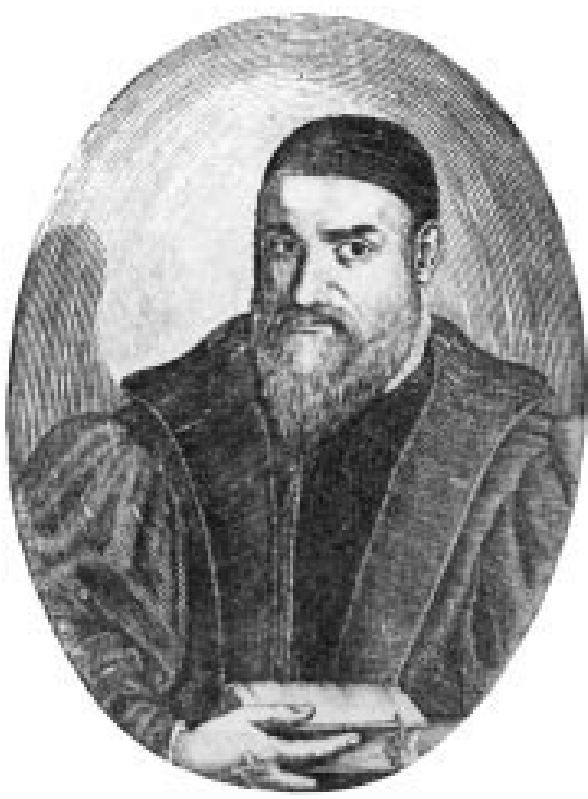

Figure 2 Gabriele Fallopius, 1523-1562.

with murder by the Inquisition, because, on undertaking a postmortem examination of a nobleman who had first died, the heart was found to be still beating feebly. Fortunately the King intervened and commuted the sentence to a pilgrimage to the Holy Land. While in Jerusalem, he heard of Fallopius' death together with an offer to accept again the professorship

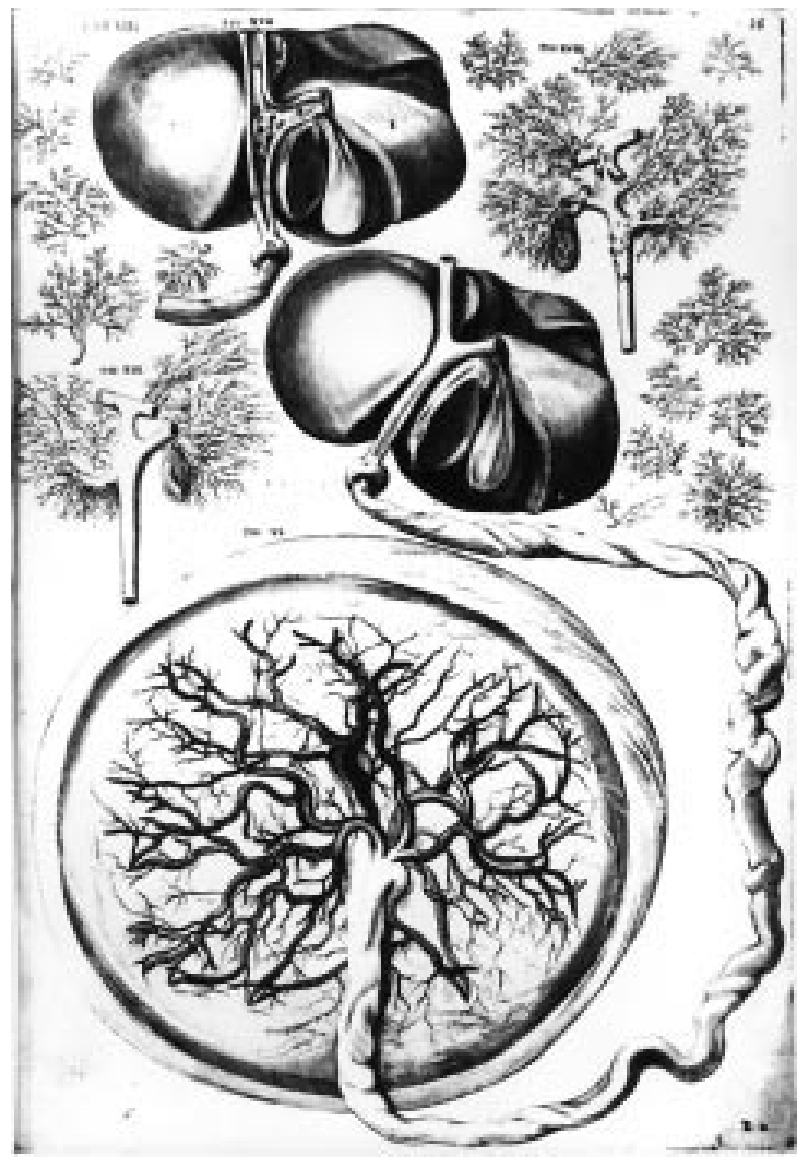

Figure 3 Placenta, umbilical cord, liver, and ductus venosus (from Fabricius' De formato foetu (1600)). at Padua. Alas, his boat was wrecked on the return journey and he died, possibly of typhus, on the island of Zante. ${ }^{1}$

Vesalius was followed in Padua by his friend and supporter, Gabriele Fallopius (1523-1562). ${ }^{14} \mathrm{He}$ had been born in Modena in North Italy in 1523 and had held an ecclesiastical appointment in the city's cathedral before studying medicine in Ferrara. After qualification, he taught anatomy there before being appointed professor of anatomy at the University of Pisa in 1548. Three years later he was invited to become professor of anatomy, surgery, and botany at the University of Padua (fig 2 ) at the instance of Cosimo I de Medici, the Grand Duke of Tuscany. There he worked until his death from pleurisy in 1562. A year earlier he had published a remarkable text Observations anatomicae. ${ }^{5}$ Many discoveries were revealed in it, especially with respect to the head and inner ear and the reproductive system. Among the reproductive terms still in use and coined by him are placenta, clitoris (which he was the first to describe), vagina, corpus luteum, and fallopian tubes. With regard to the fetal cardiovascular system, Fallopius improved on Galen's description of the ductus arteriosus and also pointed out that the human umbilical arteries were usually two in number while the vein was single.

For completeness, mention should be made at this point of Giulio Cesare Aranzi (1530-89), professor of medicine and surgery in Bologna who had studied under Vesalius in Padua. In 1564 he described the placenta as a "uterine liver" and stated that the uterine vascular ramification appeared to be separate from that of the umbilical vessels, a critical observation confirmed first by William Harvey ${ }^{6}$ in 1651 and later by William Hunter ${ }^{7}$ in 1774.

Hieronymus Fabricius was born in Acquapendente near Orvieto in 1537. ${ }^{1}$ Sent by his parents to study medicine in Padua, he was a favourite pupil of Fallopius, becoming his demonstrator in 1557 and succeeding him in the chair of anatomy and surgery in 1562 at the age of 25 , a post he then held for 47 years. The Senate of Venice built a spacious anatomical theatre for him bearing his name, which is still preserved. He was also created a Knight of St Mark and died in 1619.

Among Fabricius' numerous writings was his famous $D e$ formato foetu (On the formation of the fetus $)^{8}$ published in Venice in 1600. In this beautifully illustrated book, he drew together all the observations previously made on the fetal cardiovascular system including the human placenta, the umbilical

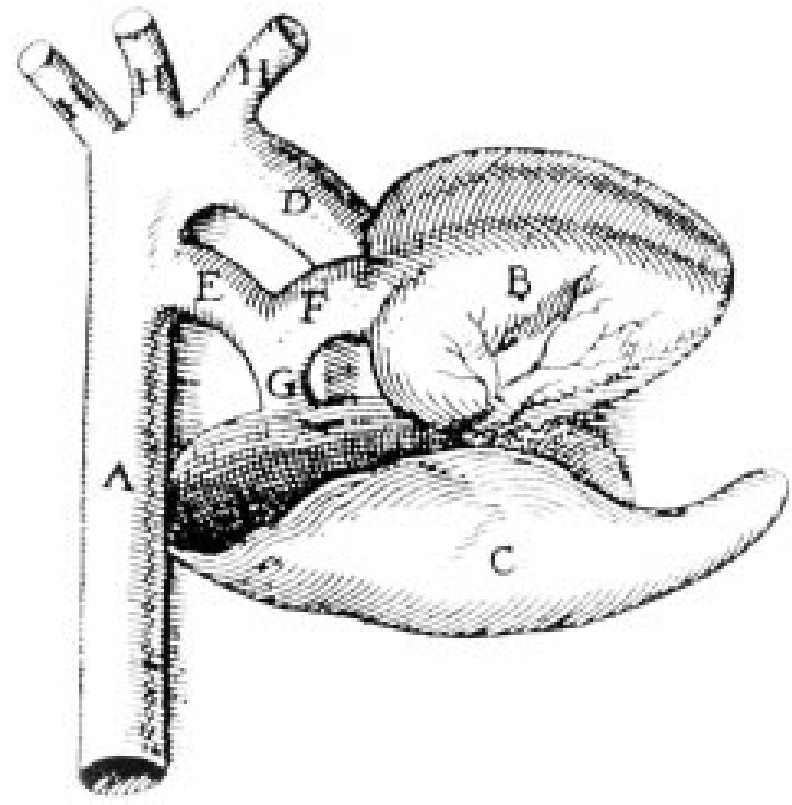

Figure 4 Heart, lung, great vessels, and ductus arteriosus (E) (from Fabricius' De formato foetu (1600)). 
vessels, the ductus venosus (fig 3), the foramen ovale and its valve (originally described by Galen), and the ductus arteriosus (fig 4). ${ }^{3}$ The book also included the results of wide comparative anatomical studies on animals, including the fetal lamb. Indeed Fabricius may be considered the founder of comparative embryology.

In 1603 Fabricius published De venarum ostiolis (On the valves of the veins). In this he provided the first clear description of the semi-lunar valves of the veins, which later gave William Harvey $^{6}$ (his pupil for two years at the turn of the century) the clue that led him to study and then describe the circulation of blood. (These valves were probably known to Eristratus of Alexandria (310-250 BC)).

\section{REFERENCES}

1 Mettler CC. History of medicine. Philadelphia: The Blakiston Co, 1947:40-51.

2 Versalius A. De humani corporis fabrica libri septum. Basel, 1543.

3 Franklin KJ. A survey of the growth of knowledge about certain parts of the foetal cardio-vascular apparatus and about the foetal circulation, in man and some other animals. Part I. Galen to Harvey. Ann Sci $1941 ; 5: 57-89$.

4 Speert H. Gabriele Fallopio and the Fallopian tubes. In: Obstetric and gynecologic milestones. London: Parthenon Publishing Co, 1996:81-3. 5 Fallopius G. Observationes anatomicae. 1561

6 Dunn PM. Dr William Harvey (1578-1657): physician, obstetrician and fetal physiologist. Arch Dis Child 1991;65:1098-100.

7 Hunter W. The anatomy of the gravid uterus. Birmingham: Baskerville, 1774.

8 Fabricius ab Aquapendente H. De formato foetu. Venice, 1600.

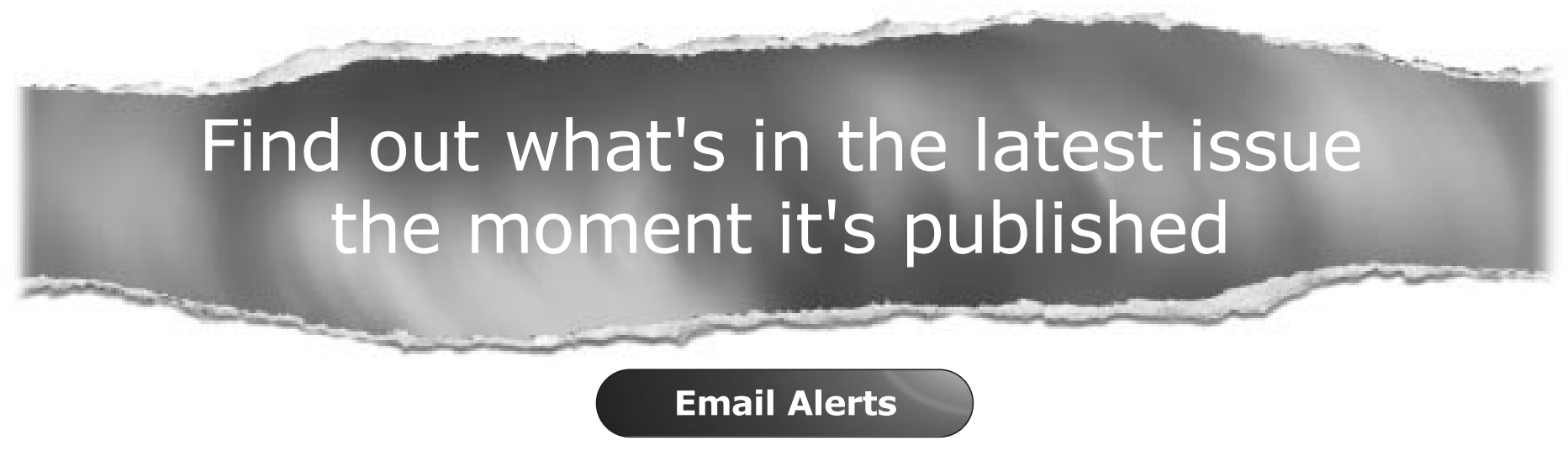

Sign up to receive the table of contents by email every month. You can select from three alerts: Table of Contents (full), TOC Awareness (notice only); Archives of Disease in Childhood related announcements. 